\section{Intracranial symptomatic giant arachnoid cyst}

\author{
SAID LARIBI • OLFAWWLHA CHAKROUN - NICOLAS SEGAL • \\ SELMA HAMDI • PATRICK PLAISANCE
}

\section{Introduction}

Intracranial arachnoid cysts are congenital compartments. They are frequently localized in the middle fossa and are intimately bordered by the arachnoid membrane. $(1,2)$ Clinical symptoms appear commonly at an early age. Cases of symptomatic arachnoid cysts are rare in the elderly. $(1,3,4)$

In this case report, we describe clinical and radiological signs of a 66 year old patient presenting with a giant suprasellar arachnoid cyst. Treatment options are discussed.

\section{Case report}

A 66-year old man presented to our emergency department suffering from vertigo. He had no medical history of infection or cerebral trauma and no previous disease.

He described a 3 week history of vertigo, diplopia and behavioural disturbances, including somnolence and fatigue. He also complained of memory disturbances, which had been present for a year. The patient denied any history of headache, emesis, or impairment of consciousness.

Except for diplopia, neurological examination in the emergency department was normal, without any focal neurological deficits or clinical evidence of vertigo. The Glasgow Coma Scale was
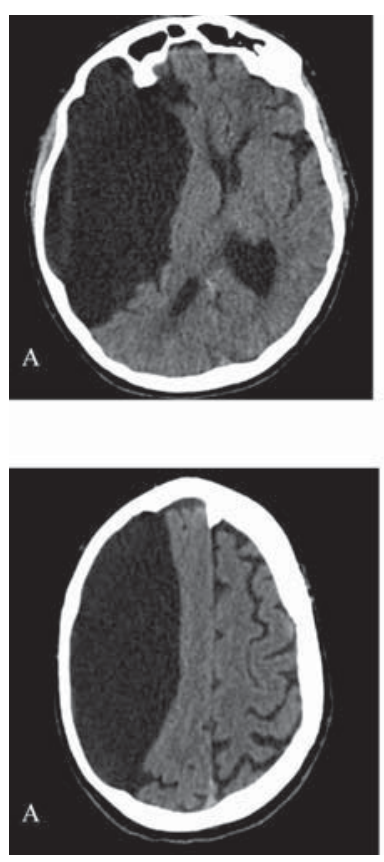
stration. normal, as were the deep tendon reflexes. Optic fundi were normal.

Cranial Computed Tomography (CCT) revealed a right hemispheric low density area with a midline and ventricle shift to the left (figures 1,2).

The patient was admitted to the neu-
SAID LARIBI $(\square) \cdot$ OLFA WALHA-CHAKROUN • NICOLAS SEGAL • SELMA HAMDI • PATRICK PLAISANCE Department of Emergency Medicine Groupe hospitalier Saint-Louis - Lariboisic̀re Fernand Widal, APHP 2 rue Ambroise Paré 75010 Paris, France Phone: + 33149958242

Fax: + 33149958545 E-mail: said.laribi@lrb.aphp.fr
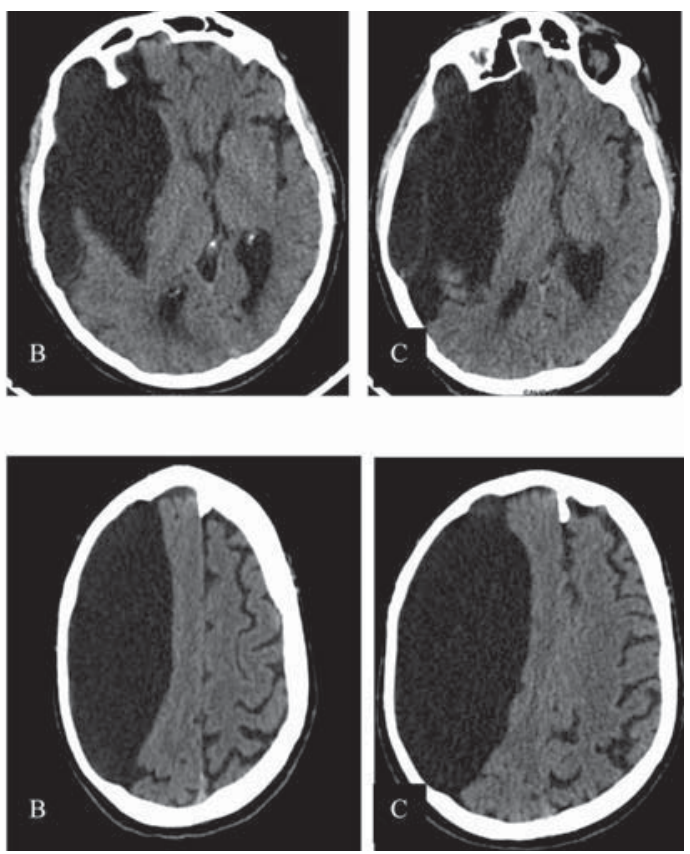

Figure 1. Cranial computed tomography (CCT).

A. First CT, before any cerebrospinal fluid (CSF) aspiration.

B. Second CCT, after the first CSF aspiration through the craniotomy fene-

C. CCT, 6 months later and following 12 CSF aspirations. 

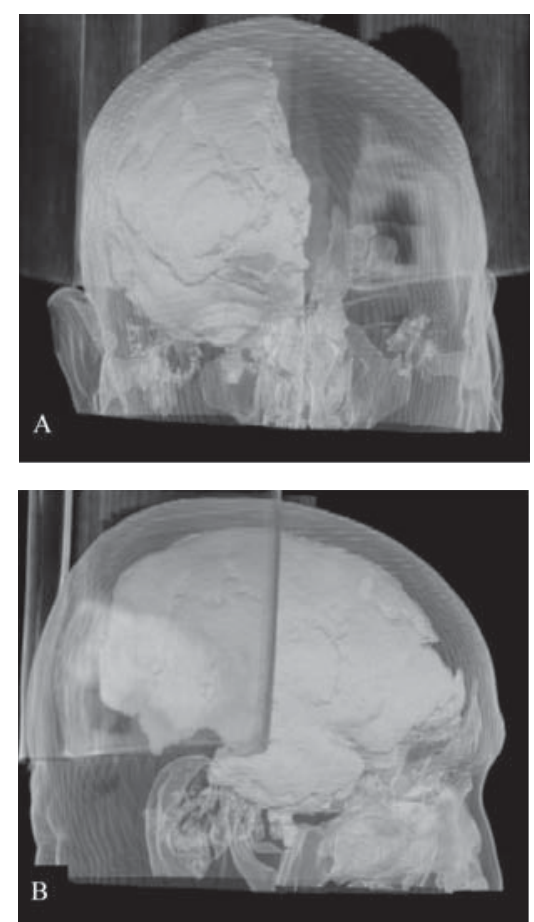

Figure 2. Cranial computed tomography 3D reconstruction, after the first cerebrospinal fluid aspiration. A front view.

B lateral view.

exam remained unchanged after each aspiration and no changes were found in the CCT images, analyzed after each aspiration.

The patient was discharged 8 days after surgery. Memory disturbances disappeared, but he continued to feel lethargic. The patient was followedup for one year, with three hospitalisations- at one, six and nine months- for recurrence of vertigo. Three to four CSF aspirations were performed during each hospitalisation, resulting in marked improvement of the patient's neurological disturbances.

\section{Discussion}

Arachnoid cysts are compartments filled with fluid almost identical to CSF and bordered by the arachnoid membrane. $(1,5)$ Their incidence is close to $1 \%$ of all intracranial masses. $(6,7)$ To our knowledge, fewer than 60 cases of symptomatic arachnoid cysts have been reported. (8) Symptoms of arachnoid cysts include headache, motor and neuropsychological disorders, sometimes resulting in seizures. In our case, even though the patient's cyst was huge, he had no evidence of seizure activity. Four mechanisms explaining the re-filling of the fluid-filled cyst have been reported: (2) a difference in the osmotic pressure of the cystic cavity and the subarachnoid space; (3) fluid secretion from the wall of the cyst; $(2,9)$ the presence of clefts with a one-way valve mechanism that allows fluid to enter the cyst and, (10) pulsation of intracystic fluid of venous or arterial origin. (2) Development of the cyst is probably associated with one of these mechanisms. Arachnoidal cysts probably develop at a very slow rate, explaining the absence of symptoms for many years, as in our case.

Treatment options are still controversial: some authors believe that the benefits of surgery are not proven and therefore that surgery is not justified when the cyst is asymptomatic or when the symptoms are not severe. In other reports, surgery was judged necessary when the cyst was crossed by bridging vessels, to avoid hemorrhagic complications, even in the absence of symptoms were. $(2,3)$ If surgery is indicated, as in our case, the choice of technique is also controversial. The aim of surgery is to reduce the pressure exerted by the arachnoid cyst on adjacent brain structures, and to reduce symptoms. (1) The reported techniques for cyst surgery are stereotactic aspiration, craniotomy and cyst wall excision or fenestration, shunting of the cyst to the peritoneal cavity, and endoscopic fenestration of the cyst to the ventricles or the subarachnoid space. $(1,2,6)$ The technique chosen in our case was craniotomy with fenestration. In view of the size of the cyst in our patient, this technique was chosen to avoid rapid decompression of brain tissue surrounding the cyst, seizures and worsening of symptoms already present. The aim of surgery in our case was to have a fenestration allowing aspiration of CSF fluid each time the patient had recurrent symptoms without risking excessive drainage. The other procedures have their own advantages: direct surgery with excision of the cyst wall is a good technique with a low risk of recurrence, $(11,12)$ a cysto-peritoneal shunt is a simple technique with low morbidity, (2) and the endoscopic shunt seems to be an interesting procedure with good outcomes. $(1,2)$ However, each one of these procedures has potential disadvantages such as rapid drainage with direct surgery, infection, obstruction or over drainage with a cysto- peritoneal shunt and vessel damages with the endoscopic shunt. $(2,12)$ None of these procedures are universally successful. In our case, CSF fluid aspiration was tolerated, with no side effects. The absence of long term follow-up has prevented us from defining the optimal surgical technique and indication.

\section{Conclusion}

Symptomatic arachnoid cysts remain rare in the elderly, which is probably due to their very slow development. Symptoms usually consist of headaches, with or without seizures or neuropsychological disturbances. Their management is still controversial; if surgical treatment is decided many techniques are possible with no consensual indication, probably because of the absence of long term follow-up. 


\section{REFERENCES}

1. Kotil K, Balci N, Bilge T. Intracranial Symptomatic Giant Arachnoid Cyst of the Interhemispheric Fissure Presenting With Frontal Lobe Syndrome. Tur Neurosur 2007;17:147-51.

2. Yamasaki F, Kodama Y, Hotta T, Taniguchi E, Eguchi K, Yoshioka H, et al. Interhemispheric arachnoid cyst in the elderly: case report and rexiew of the literature. Surg Neurol 2003;59:68-74.

3. Dyck P, Gruskin P. Supratentorial arachnoid cysts in adults. A discussion of two cases from a pathophysilogic and surgical perspective. Arch Neurol 1977;34:276-9.

4 Caruso R, Salvati M, Cervoni L. Primary intracranial arachnoïd cyst in the elderly. Neurosurg rev 1994;17:195 -8.

5. Hirohata M, Matsuo H, Miyagi J. Interhemispheric arachnoid cyst; report of three cases. No Shinkei Geka 1992;20(6):701-5.

6. Rao G, Anderson RC, Feldstein NA, Brockmeyer DL. Expansion of arachnoid cysts in children: report of two cases and review of the literature. J Neurosurg 2005;102(3 Suppl):314-7.

7. Tsurushima H, Harakuni T, Saito A. Symptomatic arachnoid cyst of the left frontal convexity presenting with memory disturbance--case report. Neurol Med Chir 2000;40(6):339-41.

8. Suzuki M, Tamaki T, Toda S, Tsuchiya M, Kogure K, Hosone M, et al. Delayed recurrent arachnoid cyst of the occipital convexity, case report. Neurol Med Chir 2009;49:134-7.

9. Go KG, Houthoff HJ, Blaauw EH, Havinga P, Hartsuiker J. Arachnoid cysts of the sylvian fissure. Evidence of fluid secretion. J Neurosurg 1984;60:803-13.

10. Shurtleff DB, Stuntz JT, Hayden PW. Experience with 1201 cerebrospinal fluid shunt procedures. Pediatr Neurosci 1985-86;12:49-57.

11. Cilluffo JM, Onofrio BM, Miller RH. The diagnosis and surgical treatment of intracranial arachnoid cysts. Acta Neurochir 1983;67:215-29.

12. Ciricillo SF, Cogen PH, Harsh GR, Edwards MS. Intracranial arachnoid cysts in children. A comparison of the effects of fenestration and shunting. J Neurosurg 1991;74:230-5. 